\title{
High-Temperature Corrosion and Mechanical Properties of Protective Scales on Incoloy 800H: The Influence of Preoxidation and Ion Implantation
}

\author{
E. A. Polman, ${ }^{*}$ T. Fransen, ${ }^{*} \dagger$ and P. J. Gellings* \\ Received February 21, 1989; revised July 20, 1989
}

Coatings, obtained by preoxidation of Incoloy $800 \mathrm{H}$ at low $\mathrm{PO}_{2}$ show good sulphidation resistance due to the higher chromia content in the oxide scale. Yttrium-ion implantation of Incoloy $800 \mathrm{H}$ has also a beneficial effect on sulphidation, if preoxidation is applied. The reason for this is presumably the segregation of yttrium to grain boundaries of the oxide. Furthermore, the oxidation kinetics of Incoloy $800 \mathrm{H}$ are independent of the partial pressure of the oxygen. Mechanical testing of the preformed oxide scale/substrate combinations in air at $600^{\circ} \mathrm{C}$ by means of constant-extension-rate experiments shows that preoxidation at low partial pressures of oxygen leads to earlier scalecracking.

KEY WORDS: Incoloy $800 \mathrm{H}$; oxidation; sulphidation; ion implantation; CER.

\section{INTRODUCTION}

The use of rare earth elements such as cerium, lanthanum, and europium and also additions of yttrium in plasma-sprayed coatings, ${ }^{1,2}$ in sol-gel coatings, ${ }^{1-4}$ and by ion implantation, ${ }^{5-8}$ have been shown to give improved resistance against high-temperature corrosion. Yttrium or cerium, implanted at a dose of $10^{16}$ to $10^{17}$ ions $/ \mathrm{cm}^{2}$, also increases the oxidation resistance of chromia-forming alloys. ${ }^{5-8}$

Recently, a beneficial effect of yttrium-ion implantation in Incoloy $800 \mathrm{H}$ toward sulphidation was reported. ${ }^{9,10}$ The application of an oxidizing pretreatment is essential, since ion-implanted nonpreoxidized samples offer

\footnotetext{
* Department of Chemical Technology, University of Twente, P.O. Box 217, 7500 AE Enschede, The Netherlands.

†To whom correspondence should be addressed.
} 
no protection against sulphidation. It has been shown previously by several authors ${ }^{1,11}$ that preoxidation at low-oxygen partial pressures of aluminaand chromia-forming alloys has a beneficial effect on the sulphidation resistance.

In this paper, the composition of the oxide scale after oxidation in oxygen of Incoloy $800 \mathrm{H}$ and the distribution of the implanted yttrium in the oxide is reported and discussed in order to better understand the role of yttrium in the corrosion process. Other main issues in this paper are the mechanical behavior and the protective properties of the oxide which is formed after oxidation of Incoloy $800 \mathrm{H}$ at various oxygen partial pressures. The determination of the oxide composition is essential in the explanation of the observed effects.

\section{EXPERIMENTAL DETAILS}

Incoloy $800 \mathrm{H}$ was received as bar material with the following composition: 20 wt. $\% \mathrm{Cr}, 32 \mathrm{wt} \% \mathrm{Ni}, 1 \mathrm{wt} \% \mathrm{Mn}, 0.4 \mathrm{wt} . \% \mathrm{Ti}$, balance Fe. The material was heat-treated at $1100^{\circ} \mathrm{C}$ and $950^{\circ} \mathrm{C}$, followed by quenching in water of $20^{\circ} \mathrm{C}$. The heat-treated bars were machined to cylindrical samples (20 $\mathrm{mm}$ length and $5 \mathrm{~mm}$ diameter) and disks (12 $\mathrm{mm}$ diameter and $2 \mathrm{~mm}$ thickness). The cylindrical samples were used to study the oxidation and sulphidation resistance in different atmospheres, and the disks were used for surface analytical investigations. The samples were ground on emery paper to a final size of 4000 grit followed by a polishing treatment on $\mathrm{Al}_{2} \mathrm{O}_{3}(0.05 \mu \mathrm{m})$. Finally, they were ultrasonically cleaned in ethanol.

Oxidation tests were carried out in a Setaram thermobalance at $900^{\circ} \mathrm{C}$ and $960^{\circ} \mathrm{C}$ in pure oxygen, at $900^{\circ} \mathrm{C}$ in a gas mixture of $1 \% \mathrm{CO}$ in $\mathrm{CO}_{2}$, and in a mixture of hydrogen and $1.5 \mathrm{~mol} \%$ water. The oxygen partial pressures in these mixtures are $1.0 \times 10^{-12}$ and $9.8 \times 10^{-21}$ bar, respectively.

Sulphidation tests were carried out in a Cahn-1000 thermobalance in three different atmospheres. At $560^{\circ} \mathrm{C}$ and at $625^{\circ} \mathrm{C}$, argon gas, flowing at a rate of $111 / \mathrm{hr}$, was mixed with a gas consisting of $95 \% \mathrm{H}_{2}$ and $5 \% \mathrm{H}_{2} \mathrm{~S}$, flowing at a rate of $3 \mathrm{l} / \mathrm{hr}$. Another gas mixture was obtained by bubbling the argon through water at $15^{\circ} \mathrm{C}$ before adding the $\mathrm{H}_{2} \mathrm{~S}$, the sulphidation test being carried out at $640^{\circ} \mathrm{C}$.

Prior to sulphidation, several preoxidation treatments were applied. The unimplanted samples were oxidized for $1 \mathrm{hr}$ at $960^{\circ} \mathrm{C}$. The calculated oxygen and sulphur partial pressures of these gas mixtures are listed in Table I, assuming an oxygen impurity of $1 \mathrm{ppm}$ in the argon. ${ }^{12}$

Cylindrical samples as well as disks were implanted with an energy of $110 \mathrm{keV}$, using the implantation facility at the University of Groningen. The source used was $\mathrm{Y}_{2} \mathrm{O}_{3}+\mathrm{CCl}_{4}$. 
Table I. Initial Gas Compositions and Calculated Partial Pressures

\begin{tabular}{cccccccc}
\hline Medium & Temp $\left({ }^{\circ} \mathrm{C}\right)$ & $\% \mathrm{H}_{2}$ & $\% \mathrm{H}_{2} \mathrm{~S}$ & $\% \mathrm{H}_{2} \mathrm{O}$ & $\% \mathrm{Ar}$ & $\mathrm{PO}_{2}(\mathrm{bar})$ & $\mathrm{Ps}_{2}(\mathrm{bar})$ \\
\hline 1 & 560 & 20.4 & 1.1 & 0 & bal. & $3.8 \times 10^{-36}$ & $1.8 \times 10^{-9}$ \\
2 & 625 & 20.4 & 1.1 & 0 & bal. & $5.5 \times 10^{-34}$ & $1.2 \times 10^{-8}$ \\
3 & 640 & 20.4 & 1.1 & 1.3 & bal. & $8.5 \times 10^{-26}$ & $1.7 \times 10^{-8}$ \\
\hline
\end{tabular}

Scanning electron microscopy (SEM) and energy dispersive X-ray analysis of the oxide and sulphide scales were performed with a JEOL M35 $\mathrm{CF}$ instrument. The phase compositions of the oxide scales were investigated by means of X-ray diffraction.

Semiquantitative analyses of the oxide scales were obtained by XPS analysis on a VG-ESCA3-MK2, using a twin anode of $\mathrm{Al}$ and $\mathrm{Mg}$. The spectra obtained after several Ar-sputtering cycles also give information of the binding states of the atoms. The sputter rate was about $60 \AA / \mathrm{min}$.

SIMS analysis was performed on a ARL-IMMA instrument, using $\mathrm{N}_{2}^{+}$ ions to make a depth profile of the oxide scale. The sputter time was approximately $50 \AA / \mathrm{sec}$.

Constant-extension-rate (CER) tests were carried out on specimens with a gage diameter of $2.50 \mathrm{~mm}$ and an effective gage length of $35.0 \mathrm{~mm}$. The specimens were preoxidized for $3 \mathrm{hr}$ at $900^{\circ} \mathrm{C}$ using the same atmospheres as mentioned earlier. After $3 \mathrm{hr}$ an oxide thickness of approximately $1 \mu \mathrm{m}$ was obtained. The CER equipment consisted of a fixed frame, a carriage, a drive mechanism, a load cell, and a recorder. The tests were performed in air at a temperature of $600^{\circ} \mathrm{C}$. An extension rate of $4 \times 10^{-7} \mathrm{sec}^{-1}$ was applied. The strain-to-cracking value was determined by scanning electron microscopy after applying the strain.

\section{RESULTS}

\section{Oxidation Tests}

Oxidation tests of cylindrical samples in pure oxygen $(\mathrm{P}=1 \mathrm{bar})$ at $960^{\circ} \mathrm{C}$ show that implantation of $10^{16}$ yttrium ions $\mathrm{cm}^{-2}$ in Incoloy $800 \mathrm{H}$, leads to a reduction of the oxidation rate. Both before and after implantation the oxidation behavior is approximately parabolic (see Fig. 1).

The $k_{p}$ values are $(7.9 \pm 0.2) \times 10^{-12} \mathrm{~g}^{2} \mathrm{~cm}^{-4} \mathrm{sec}^{-1}$ for the nonimplanted alloy and $(1.6 \pm 0.1) \times 10^{-12} \mathrm{~g}^{2} \mathrm{~cm}^{-4} \mathrm{sec}^{-1}$ for the yttrium-implanted material. For the calculation of the $k_{p}$ values, the first $30 \mathrm{~min}$ of the oxidation were not taken into account.

In order to determine the influence of the oxygen partial pressure on the oxidation behavior, thermogravimetric measurements at $900^{\circ} \mathrm{C}$ were 


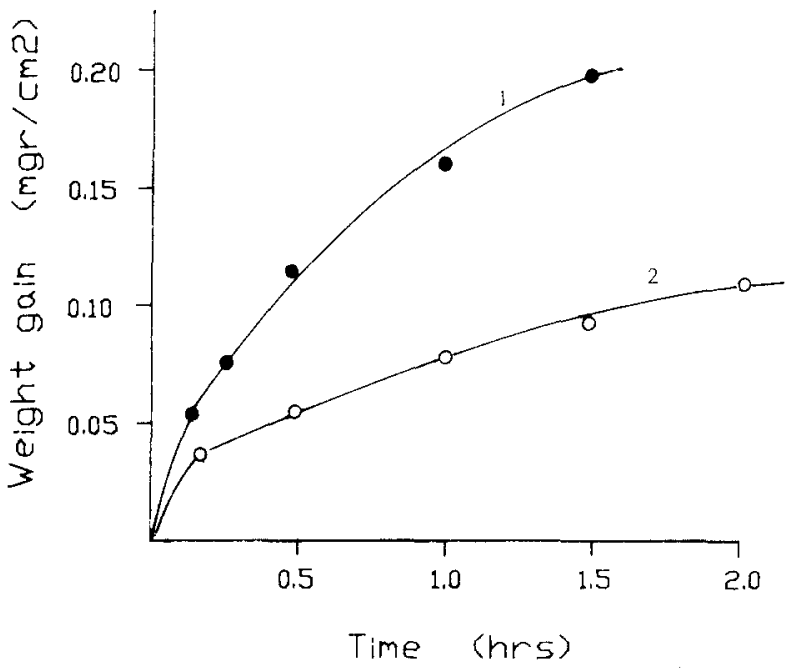

Fig. 1. Oxidation in $\mathrm{O}_{2}$ at $960^{\circ} \mathrm{C}$ of Incoloy $800 \mathrm{H}, 1=$ blank; $2=\mathrm{Y}$-implanted at a dose of $10^{16} \mathrm{~cm}^{-2}$.

performed on nonimplanted samples. No significant reduction in oxidation rate is obtained for oxidation of Incoloy $800 \mathrm{H}$ at a $\mathrm{Po}_{2}$ of $9.8 \times 10^{-21}$ bar, compared to oxidation in $\mathrm{CO} / \mathrm{CO}_{2}\left(\mathrm{PO}_{2}=10^{-14}\right)$ as well as for oxidation in $\mathrm{O}_{2}$ at $900^{\circ} \mathrm{C}$. All oxidation tests show parabolic kinetics. The results of the oxidation tests at various partial pressures are given in Table II.

The oxygen partial pressure independence of the oxidation kinetics was previously observed by Hindam and Whittle for a chromium-nickel alloy at $900^{\circ} \mathrm{C}$. The kinetics were only investigated in a small oxygen partial pressure range (from $8 \times 10^{-9}$ to $2 \times 10^{-14}$ bar) by using several $\mathrm{CO} / \mathrm{CO}_{2}$ mixtures. ${ }^{13}$ Hindam and Whittle also observed that the oxidation kinetics of pure chromium at $1000^{\circ} \mathrm{C}$ do not depend on the partial pressure. This was also found over a large range of oxygen pressures at $900^{\circ} \mathrm{C}$ by the present authors and will be published in a subsequent paper. ${ }^{14}$

Table II. $K_{p}$ Values in $\mathrm{g}^{2} \mathrm{~cm}^{-4} \mathrm{sec}^{-1}$

\begin{tabular}{lccc}
\hline Sample & Temp $\left({ }^{\circ} \mathrm{C}\right)$ & atm. & $k_{p}\left(\times 10^{+12}\right)$ \\
\hline Incoloy $800 \mathrm{H}$ & 960 & $\mathrm{O}_{2}$ & $7.9 \pm 0.2$ \\
Incoloy impl. $10^{16} \mathrm{Ycm}^{-2}$ & 960 & $\mathrm{O}_{2}$ & $1.6 \pm 0.1$ \\
Incoloy $800 \mathrm{H}$ & 900 & $\mathrm{O}_{2}$ & $2.0 \pm 0.2$ \\
Incoloy $800 \mathrm{H}$ & 900 & $\mathrm{CO} / \mathrm{CO}_{2}$ & $2.6 \pm 0.1$ \\
Incoloy $800 \mathrm{H}$ & 900 & $\mathrm{H}_{2} / \mathrm{H}_{2} \mathrm{O}$ & $1.5 \pm 0.4$ \\
\hline
\end{tabular}


Several oxidation tests were performed at $900^{\circ} \mathrm{C}$ in $\mathrm{H}_{2} / \mathrm{H}_{2} \mathrm{O}$ by oxidizing many samples simultaneously, without registering the weight gain during the oxidation. After $20 \mathrm{hr}$, the ratio of the weight gain of the implanted specimens compared to the nonimplanted samples was $1: 2.5$. This experiment showed that yttrium-ion implantation in Incoloy $800 \mathrm{H}$ leads to a decrease in the oxidation rate over a large range of oxygen pressures.

\section{Sulphidation Tests}

Prior to sulphidation, several preoxidation treatments were applied. The unimplanted samples were oxidized for $1 \mathrm{hr}$ at $960^{\circ} \mathrm{C}$ and the yttriumimplanted specimens were oxidized for $4 \mathrm{hr}$ at this temperature in order to obtain a similar oxide layer thickness of about $1 \mu \mathrm{m}$. At low oxygen partial pressures all samples were preoxidized for $20 \mathrm{hr}$ at $900^{\circ} \mathrm{C}$.

The sulphidation was stopped after a weight gain of approximately $1 \mathrm{mg} / \mathrm{cm}^{2}$ was reached. At this weight gain the oxide coatings can no longer be regarded as protective and the mass transport is mainly governed by locally formed sulphide ducts.

If Incoloy $800 \mathrm{H}$ is not preoxidized at all very poor sulphidation resistance is obtained as shown by Fig. 2 (curve 1). For yttrium-implanted nonpreoxidized samples, the same poor sulphidation resistance is observed (see also curve 1). Preoxidation results in the formation of a protective oxide coating (curve 2 ).

Preoxidation in oxygen of yttrium-ion-implanted samples results in better sulphidation resistance, compared to blanks (see curve 3 ). The sulphidation tests in medium 1 (Fig. 2, curve 3) and medium 3 (Fig. 4, curve 3 ) show that the corrosion rate is decreased by a factor of $5-10$.

Preoxidation at a low oxygen partial pressure leads to much better sulphidation resistance than preoxidation in oxygen. For preoxidation in $\mathrm{H}_{2} / \mathrm{H}_{2} \mathrm{O}$ the sulphidation behavior is even better than for samples preoxidized in $\mathrm{CO} / \mathrm{CO}_{2}$ (see Fig. 2, curves 5 and 4 respectively). The blank samples preoxidized in $\mathrm{H}_{2} / \mathrm{H}_{2} \mathrm{O}$ and exposed in medium 1 (Fig. 2, curve 5) and the blank and implanted samples, preoxidized in $\mathrm{H}_{2} / \mathrm{H}_{2} \mathrm{O}$ and sulphidized in medium 3 (Fig. 4, curves 2 and 4) showed no weight gain after $150 \mathrm{hr}$ and $250 \mathrm{hr}$, respectively. SEM-observations made clear that there was only a very slight localized attack by sulphur.

No difference was observed in corrosion behavior between implanted and nonimplanted samples, preoxidized at low oxygen partial pressures during sulphidation in medium 2 (Fig. 3, curves 2 and 3). The large deviation between the duplicate measurements in Fig. 3 (curves 2 and 3) may be due to the very severe corrosive atmosphere. Once the protective scale is affected, sulphidation proceeds at a high rate, and small differences in attacked area may then cause large differences in weight change. 


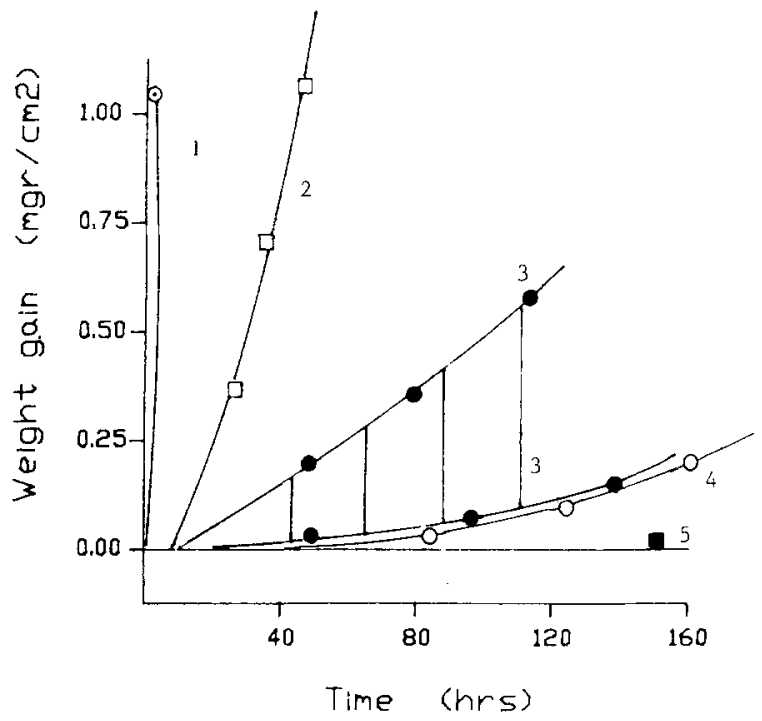

Fig. 2. Sulphidation in medium $1.1=$ blank nonpreoxidized; $2=$ blank preoxidized in $\mathrm{O}_{2} ; 3=10^{16} \mathrm{Ycm}^{-2}$ preoxidized in $\mathrm{O}_{2}$; $4=$ blank preoxidized in $\mathrm{CO} / \mathrm{CO}_{2} ; 5=$ blank preoxidized in $\mathrm{H}_{2} / \mathrm{H}_{2} \mathrm{O}$.

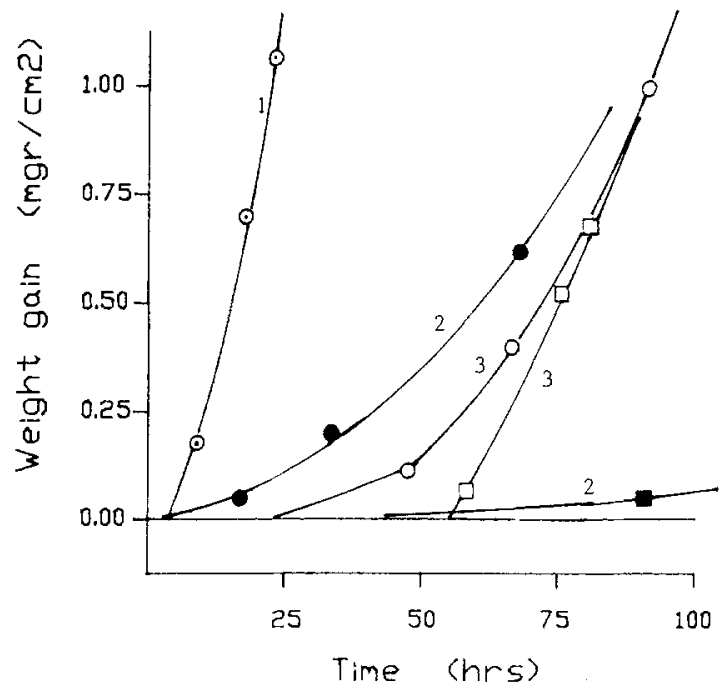

Fig. 3. Sulphidation in medium $2.1=$ blank preoxidized in $\mathrm{O}_{2} ; 2$ = blank preoxidized in $\mathrm{H}_{2} / \mathrm{H}_{2} \mathrm{O} ; 3=10^{16} \mathrm{Ycm}^{-2}$ preoxidized in $\mathrm{H}_{2} / \mathrm{H}_{2} \mathrm{O}$. 


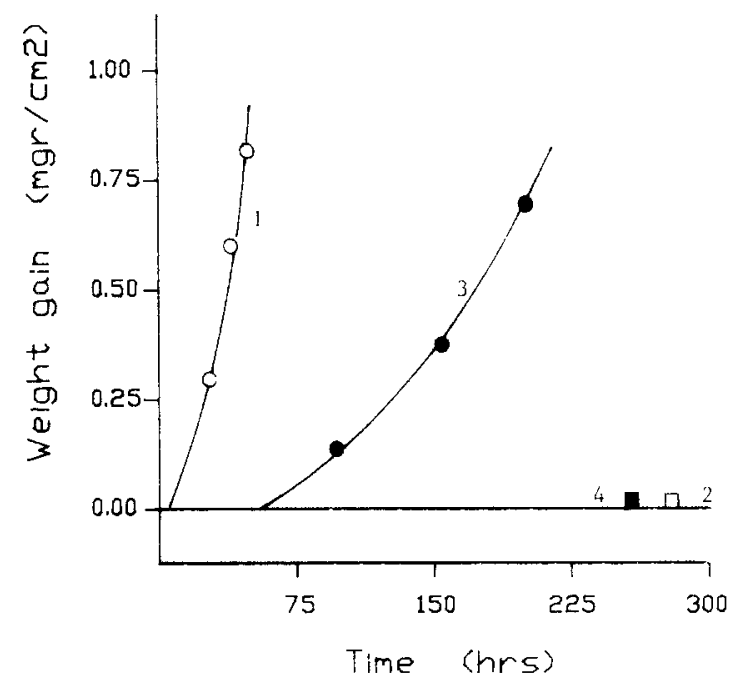

Fig. 4. Sulphidation in medium $3.1=$ blank preoxidized in $\mathrm{O}_{2} ; 2=$ blank preoxidized in $\mathrm{H}_{2} / \mathrm{H}_{2} \mathrm{O} ; 3=10^{16} \mathrm{Ycm}^{-2}$ preoxidized in $\mathrm{O}_{2} ; 4=10^{16} \mathrm{Ycm}^{-2}$ preoxidized in $\mathrm{H}_{2} / \mathrm{H}_{2} \mathrm{O}$.

\section{CER Experiments}

The CER tests performed at $600^{\circ} \mathrm{C}$ in air show that the strain-to-cracking of preoxidized scales is influenced by the preoxidizing conditions. For preoxidation in $\mathrm{O}_{2}$, the strain-to-cracking is $1.5 \%$, whereas preoxidation in $1 \% \mathrm{CO} / \mathrm{CO}_{2}$ as well as in $1.5 \% \mathrm{H}_{2} \mathrm{O} / \mathrm{H}_{2}$ leads to a strain-to-cracking of $0.75 \%$.

It was possible to detect the formation of small cracks by means of SEM. The cracks propagate perpendicular to the tensile direction. An example of a cracked oxide scale is given in Fig. 15. The oxide was formed at $900^{\circ} \mathrm{C}$ in $1 \% \mathrm{CI} / \mathrm{CO}_{2}$ and the total strain was $1 \%$. If cracking occurred, several cracks could be observed.

\section{SIMS Measurements}

By means of SIMS, small changes in concentrations of elements present at low concentrations can be determined. Because of the strong matrix effects, SIMS can only be used as a quantitative technique if a set of well-defined standards is available.

SIMS spectra of a blank and an implanted sample, both with an oxide thickness of about $1 \mu \mathrm{m}$ and both oxidized at $960^{\circ} \mathrm{C}$ in oxygen, are shown in Figs. 5 and 6. For silicon and aluminum, which are both present in 
oxide, alloy

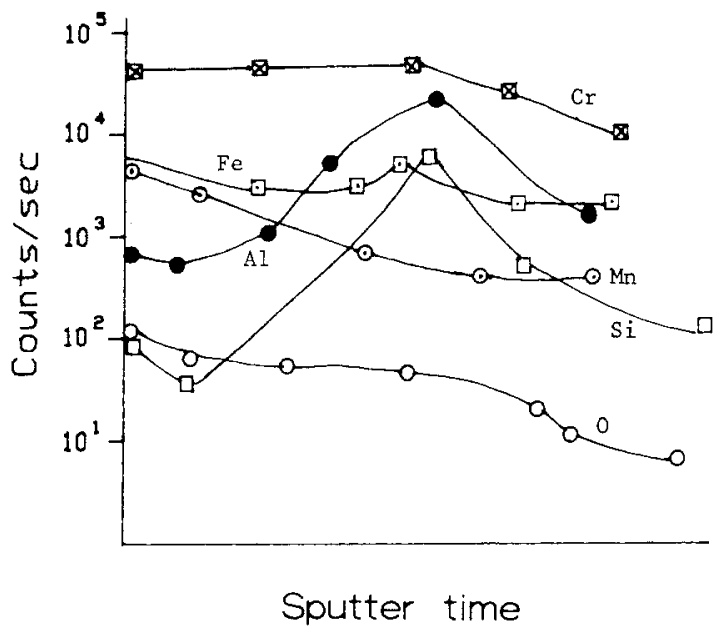

Fig. 5. SIMS depth profile for Incoloy $800 \mathrm{H}$ oxidized in $\mathrm{O}_{2}$ at $960^{\circ} \mathrm{C}$ for $1 \mathrm{hr}$.

amounts of a few tenths of a percent in the alloy, a maximum in concentration at the oxide/alloy interface is observed. Probably these elements are preferentially oxidized during the first stages of the oxidation due to their high affinity for oxygen. ${ }^{15}$

The yttrium in the oxide of the implanted alloy also has a maximum at the oxide/alloy interface. This is in disagreement with the conclusions drawn from previous Rutherford Back Scattering measurements. ${ }^{10}$ It is possible that small amounts of $\mathrm{Cu}$ or $\mathrm{Mo}$ in the outer oxide give rise to the observed RBS spectrum, since $\mathrm{Cu}$ and Mo are both present in the alloy in small amounts.

\section{XPS Measurements}

The XPS measurements were used to determine a depth profile by sputtering with argon. In measuring depth profiles, selective-sputtering effects must be taken into account. Also the oxide of Incoloy $800 \mathrm{H}$ cannot be regarded as a smooth regular surface (Fig. 11). However, changes in concentration can still be observed, and comparisons between different samples of Incoloy $800 \mathrm{H}$ are also possible. 


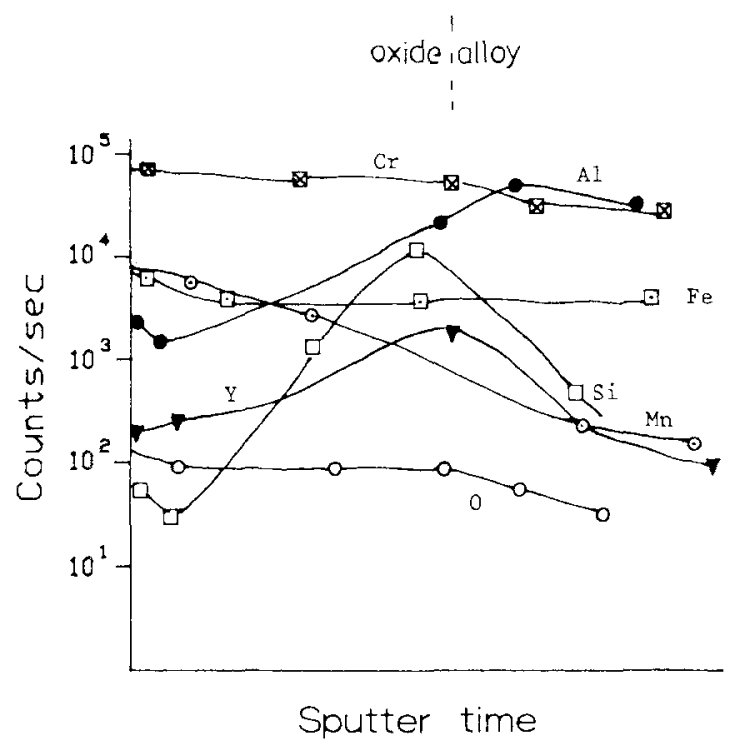

Fig. 6. SIMS depth profile for Y-implanted Incoloy $800 \mathrm{H}$, preoxidized in $\mathrm{O}_{2}$ at $960^{\circ} \mathrm{C}$ for $3 \mathrm{hr}$.

To quantify the spectra, obtained by using $\mathrm{Al}-\mathrm{K}_{a}$ radiation, the peak areas of the strong XPS signals were measured. The sensitivity factors for the peak areas were taken from Jørgensen and Berthou ${ }^{16}$ which differ in some respects from those published later by Wagner et al., ${ }^{17}$ but give more consistent results for the bulk of Incoloy $800 \mathrm{H}$, used as a standard. Corrections for interfering Auger peaks were made by also measuring some peaks with a $\mathrm{Mg}-\mathrm{K}_{a}$ radiation source. For the $\mathrm{Mg}-\mathrm{K}_{a}$ radiation, the sensitivity factors of Berthou and Jørgensen ${ }^{18}$ were also used.

The depth profiles obtained for a blank specimen oxidized in $\mathrm{O}_{2}$ at $960^{\circ} \mathrm{C}$ for $1 \mathrm{hr}$, one oxidized in $\mathrm{H}_{2} / \mathrm{H}_{2} \mathrm{O}$ at $900^{\circ} \mathrm{C}$ and a yttrium-implanted specimen oxidized in $\mathrm{O}_{2}$ at $960^{\circ} \mathrm{C}$ for $4 \mathrm{hr}$, respectively, are plotted in Figs. 7-9. The oxide/alloy interface was not very sharp due to sputtering effects and the irregularity of the interface. The position of the interface was determined by an increase in the iron and nickel contents and a slight decrease in the oxygen content.

The yttrium concentration in the oxidized implanted Incoloy $800 \mathrm{H}$ is observed to be high in the oxide at the oxide/alloy interface, but the yttrium is also present in low amounts all over the oxide scale.

The overall compositions of the oxides of the implanted and the nonimplanted alloy, oxidized in $\mathrm{O}_{2}$, are quite similar. Aluminum and 


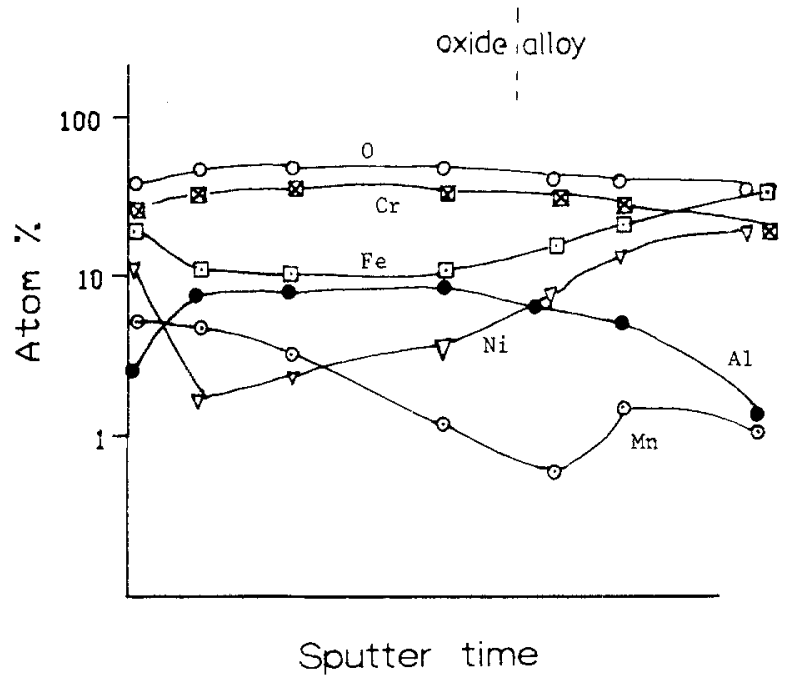

Fig. 7. XPS depth profile for Incoloy $800 \mathrm{H}$ preoxidized in $\mathrm{O}_{2}$ at $960^{\circ} \mathrm{C}$ for $1 \mathrm{hr}$.

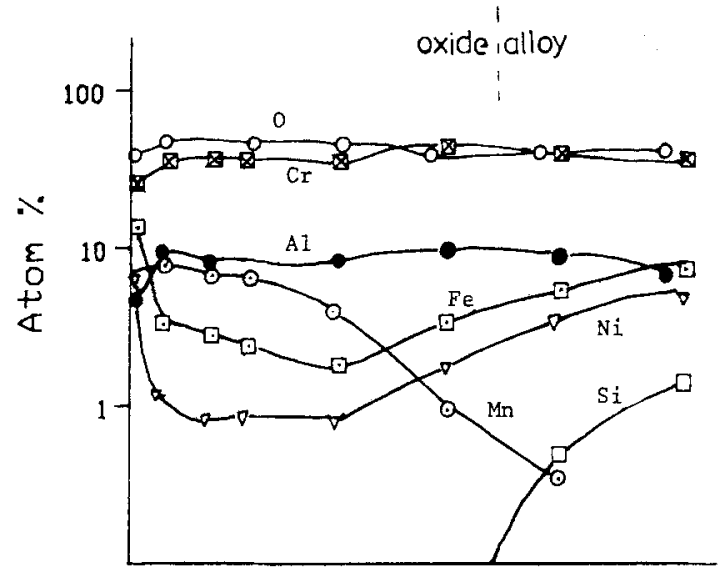

Sputter time

Fig. 8. XPS depth profile for Incoloy $800 \mathrm{H}$ preoxidized in $\mathrm{H}_{2} \mathrm{O} / \mathrm{H}_{2}$ at $900^{\circ} \mathrm{C}$ for $20 \mathrm{hr}$. 


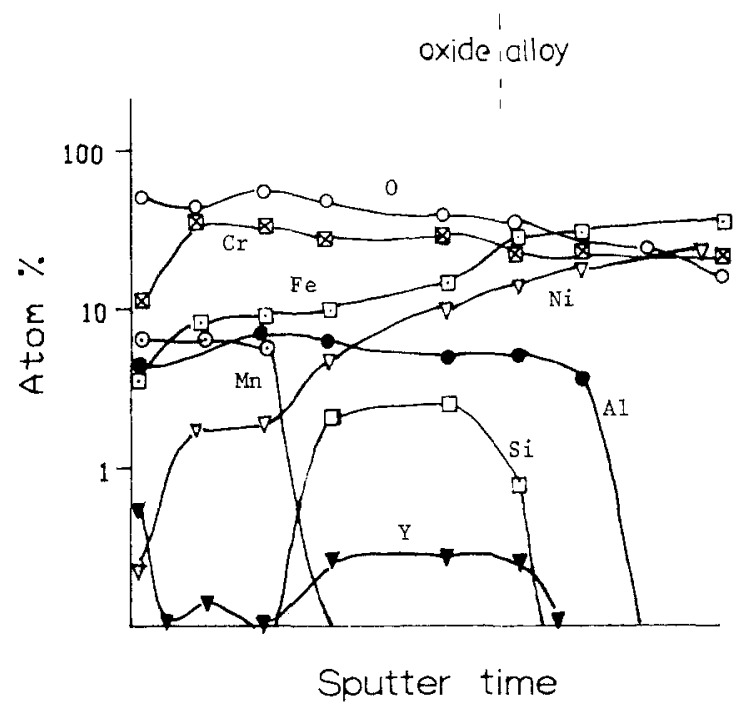

Fig. 9. XPS depth profile for Incoloy $800 \mathrm{H}$, Y-implanted, preoxidized in $\mathrm{O}_{2}$ at $960^{\circ} \mathrm{C}$ for $3 \mathrm{hr}$.

manganese are both preferentially oxidized, and aluminum and silicon again show maximum concentrations at the oxide/alloy interface. Chromium oxide is the main component in the oxide scale.

The oxide scale of the blank specimen oxidized in $\mathrm{H}_{2} / \mathrm{H}_{2} \mathrm{O}$ shows higher concentrations of chromium, aluminum, and manganese, compared with the samples oxidized in $\mathrm{O}_{2}$. This can be understood easily if the thermodynamic stability of the compounds under the oxidation conditions is taken into account. ${ }^{15}$ Chromium, aluminum, manganese, and silicon are the only elements which have stable oxide phases according to thermodynamics under these conditions. As a consequence nickel- and iron-oxide are present in lower amounts than in the oxide formed by oxidation in $\mathrm{O}_{2}$.

\section{XRD Measurements}

XRD measurements were performed on oxide scales grown on Incoloy $800 \mathrm{H}$ at $900^{\circ} \mathrm{C}$ in $\mathrm{O}_{2}$ as well as in $\mathrm{H}_{2} / \mathrm{H}_{2} \mathrm{O}$. Incoloy $800 \mathrm{H}$ was oxidized for $2 \mathrm{hr}$, resulting in an oxide thickness of about $1 \mu \mathrm{m}$.

The ratio of the surface areas of the $\mathrm{Cr}_{2} \mathrm{O}_{3}$ (104) reflection compared to the spinel (311) reflection was found to be two for both oxide types. It is understandable that at least the oxide grown in $\mathrm{H}_{2} \mathrm{O} / \mathrm{H}_{2}$ will have a lower $\mathrm{Fe}$ and $\mathrm{Ni}$ and a higher $\mathrm{Al}$ and $\mathrm{Mn}$ content, because at low $\mathrm{PO}_{2}$ the preferential oxidation of $\mathrm{Al}$ and $\mathrm{Mn}$ is larger than at higher $\mathrm{PO}_{2}$. Since 


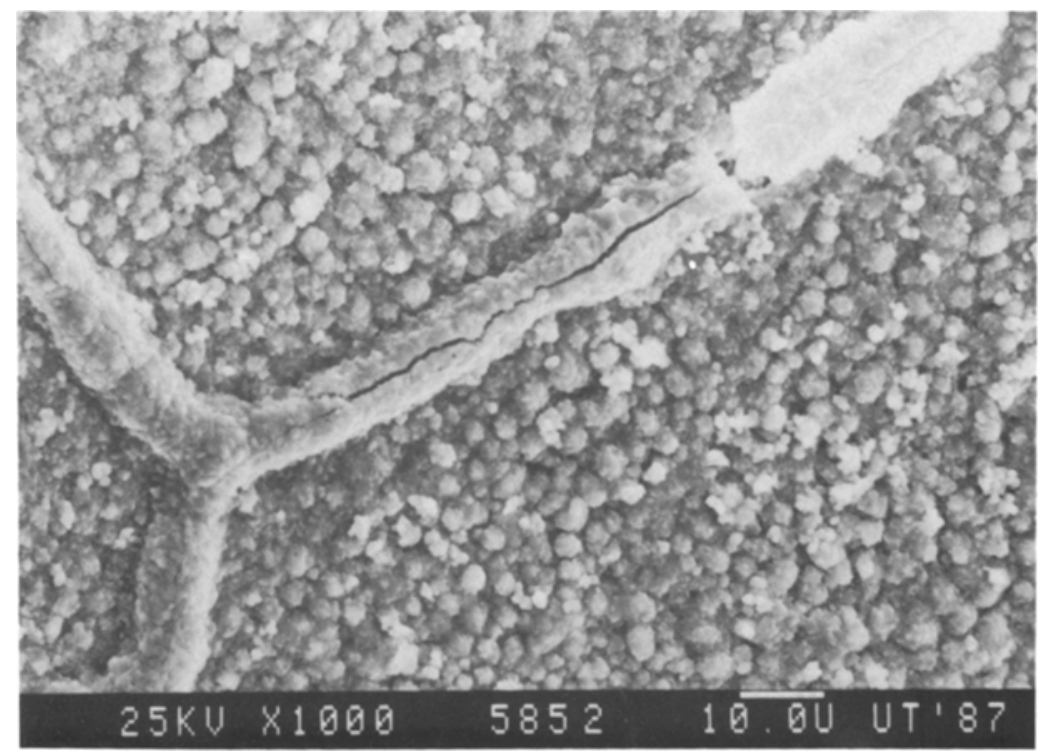

Fig. 10. Incoloy $800 \mathrm{H}$ oxidized in $\mathrm{O}_{2}$ at $960^{\circ} \mathrm{C}$ for $1 \mathrm{hr}$.

XRD does not very easily allow to distinguish between the various spinel compositions, the spectra give no further information about the oxide composition.

\section{SEM Observations}

The surface of blank specimens oxidized in $\mathrm{O}_{2}$ and of a specimen oxidized in $\mathrm{H}_{2} / \mathrm{H}_{2} \mathrm{O}$ in Fig. 10-13, respectively. The oxide obtained after oxidation in $\mathrm{H}_{2} / \mathrm{H}_{2} \mathrm{O}$ is less porous on the outside, and the outer grains are locally mutually attached.

The sample shown in Fig. 14 was preoxidized in $\mathrm{H}_{2} / \mathrm{H}_{2} \mathrm{O}$ and sulphidized for $290 \mathrm{hr}$ in medium 3 and shows only localized attack by sulphur at the thicker oxide present on the alloy grain boundaries which have been mentioned earlier as fast-diffusion paths. ${ }^{10}$ Figure 15 gives an example of a cracked oxide scale. The cracking was observed at a strain of $1 \%$ at $600^{\circ} \mathrm{C}$ after preoxidation in $1 \% \mathrm{CO} / \mathrm{CO}_{2}$ at $900^{\circ} \mathrm{C}$.

\section{DISCUSSION}

\section{Oxidation and Sulphidation Behavior}

Several mechanisms have been proposed to account for the beneficial effect of rare-earth elements in alumina- or chromia-forming oxide scales. 


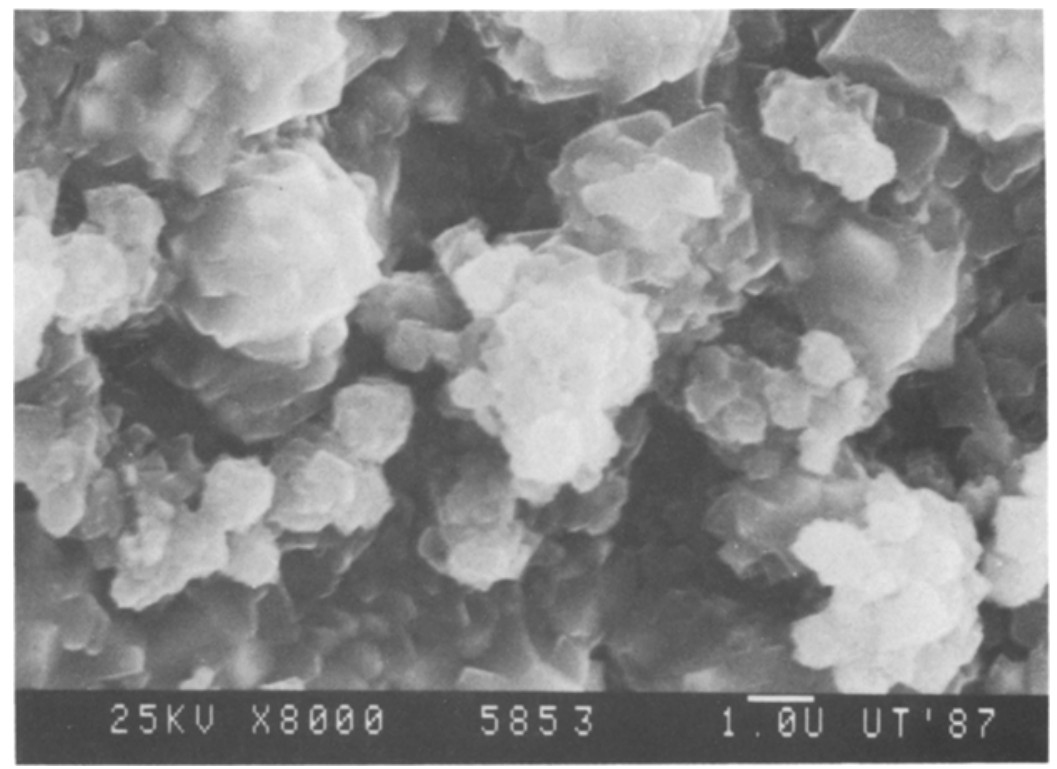

Fig. 11. Incoloy $800 \mathrm{H}$ oxidized in $\mathrm{O}_{2}$ at $960^{\circ} \mathrm{C}$ for $20 \mathrm{hr}$ (higher magnification of Fig. 10).

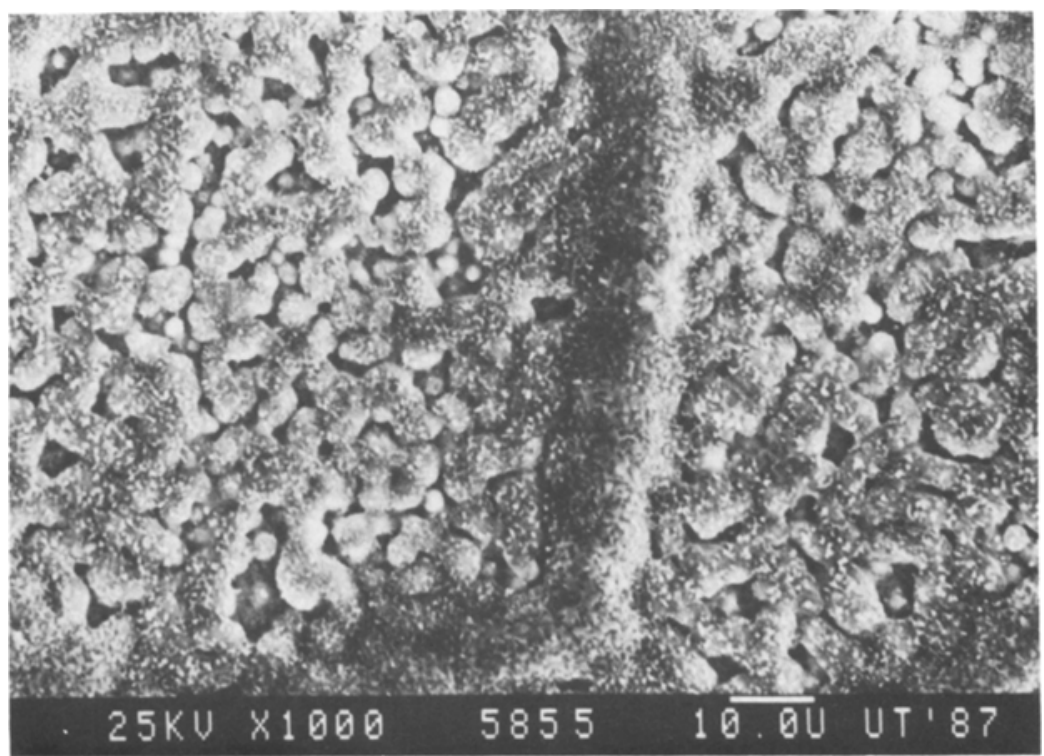

Fig. 12. Incoloy $800 \mathrm{H}$ oxidized in $\mathrm{H}_{2} \mathrm{O} / \mathrm{H}_{2}$ at $900^{\circ} \mathrm{C}$ for $20 \mathrm{hr}$. 


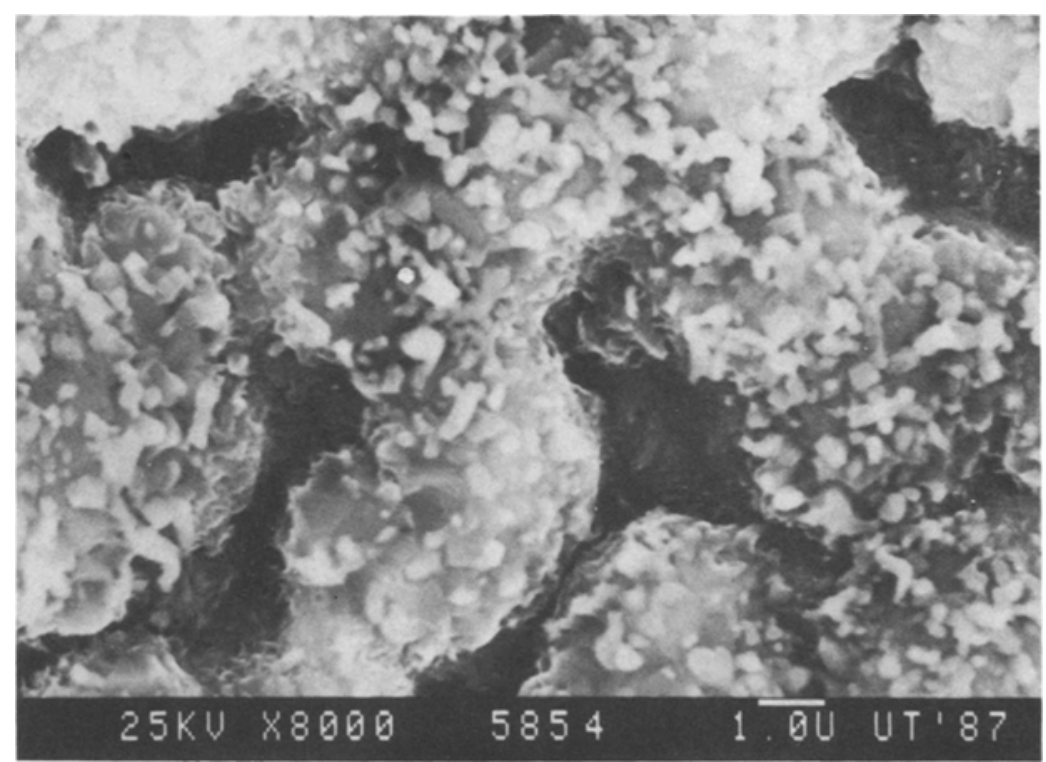

Fig. 13. Incoloy $800 \mathrm{H}$ oxidized in $\mathrm{H}_{2} \mathrm{O} / \mathrm{H}_{2}$ at $900^{\circ} \mathrm{C}$ for $20 \mathrm{hr}$ (higher magnification of Fig. 12).

These mechanisms were reviewed by Whittle and Stringer ${ }^{19}$ and recently by Moon..$^{20}$ The effects caused by the proposed mechanisms can generally be divided in three groups:

1. The effects on the initial oxidation.

2. The prevention of scale failure.

3. The reduction of the growth rate.

\section{Effects on Initial Oxidation}

According to Stringer, ${ }^{21}$ chromia grains nucleate on rare-earth dispersoids, thus forming a closed chromia layer and reducing the normally needed amount of chromium in the alloy. The SIMS and especially the XPS results in this work show that the mean compositions of the oxide on the yttriumimplanted alloy and on the blank are about the same, and that the chromium contents near the alloy/oxide interface in the oxide are very high for both samples. Therefore, it is not likely that the formation of a chromia layer in the initial stages of oxidation is playing a significant role. Also, the model is not applicable for the explanation of the beneficial effect of yttrium-ion implantation in pure chromium as observed by Cotell and Yurek. ${ }^{22}$ 


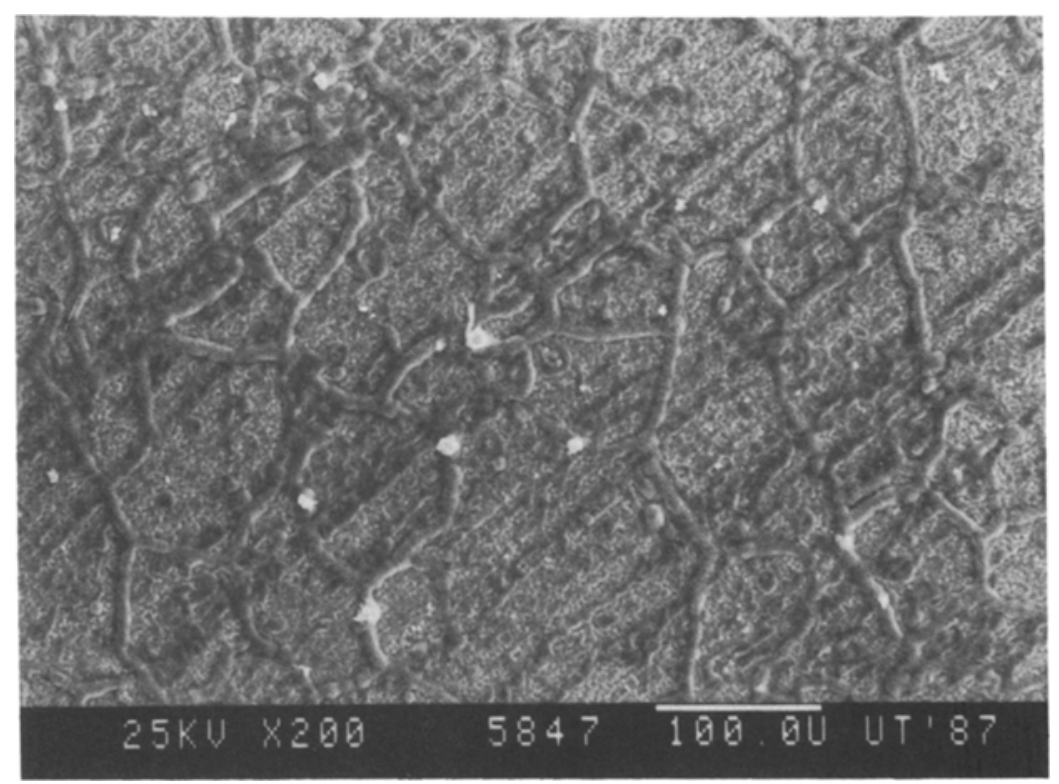

Fig. 14. Incoloy $800 \mathrm{H}$, preoxidized in $\mathrm{H}_{2} \mathrm{O} / \mathrm{H}_{2}$ for $20 \mathrm{hr}$, sulphidized for $290 \mathrm{hr}$ in medium 3 . The white spots are sulphides formed on oxide grain-boundary ridges.

\section{Prevention of Scale Failure}

Scale failures such as spalling can drastically be diminished by the additions of rare-earth elements, and several mechanisms were proposed to explain this improved behavior. However, oxide spalling never occurred for the oxide scales of the yttrium-implanted as well as for the nonimplanted Incoloy $800 \mathrm{H}$, as shown by the sensitive thermogravimetric experiments and by the SEM observations. Therefore, the prevention of scale failure does not play a role in the improved isothermal oxidation resistance of yttrium-implanted Incoloy $800 \mathrm{H}$.

\section{Reduction of Growth Rate}

In the applied corrosion tests, the blocking of fast-diffusion paths seems the only reasonable mechanism. Atkinson has shown by means of chromiumtracer-diffusion experiments on chromia single crystals that the chromium lattice diffusion in chromia can never account for the observed oxidation rates. $^{23}$ Therefore, the main transport mechanism in oxide scales on chromium and chromia-forming alloys must take place by means of fast diffusion paths such as grain boundaries. The effect of rare-earth elements on scale growth is thus generally assumed to be due to the reduction of 


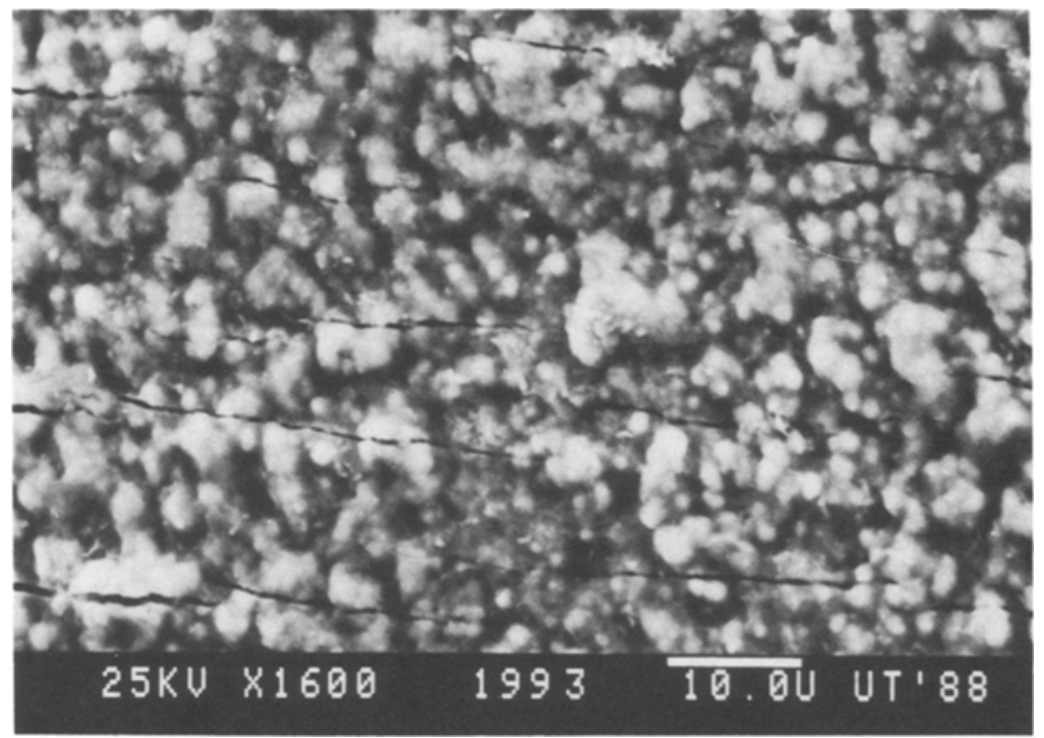

Fig. 15. Cracked oxide after application of $1 \%$ strain in air; the oxide was preformed in $\mathrm{CO} / \mathrm{CO}_{2}$ at $900^{\circ} \mathrm{C}$.

grain-boundary diffusion. Experimental support for this theory was recently given by Przybylski and Yurek who observed yttrium segregation at the boundaries of chromia grains on a yttrium-implanted cobalt-chromium alloy. ${ }^{24}$ The experiments of Cotell and Yurek for Y-implanted chromium show that the cation diffusion is more affected than the oxygen transport in the protective scale. ${ }^{22}$ Both the distribution of oxygen tracer and of the yttrium in the oxide scale after oxidation at $900^{\circ} \mathrm{C}$ show that the ratio between the oxygen and metal diffusion in the oxide scale is increased by implantation.

The exact mechanism by which rare-earth elements hinder the transport at the grain boundaries is not clear. Przybylski and Yurek suggested that the reduction of the available chromium sites at the grain boundaries might reduce the chromium transport. The diffusion of doped chromia could then be described by:

$$
D_{\mathrm{Cr}}(\mathrm{gb})=a_{\mathrm{Cr}} \times D_{\mathrm{Cr}}^{0}(\mathrm{gb}) \times \delta
$$

where $D_{\mathrm{Cr}}^{0}(\mathrm{gb})$ is the grain-boundary diffusion coefficient for chromium cations in pure chromia, $\delta$ is the grain boundary width, and $D_{\mathrm{Cr}}(\mathrm{gb})$ is the diffusion coefficient for chromium cations in yttrium-doped chromia. ${ }^{24}$ Although there is no direct evidence for this to occur, it cannot be excluded 
as long as the chromium concentration at the outer layers of the grain boundary is not exactly known.

The transport along grain boundaries may also be affected by a decrease of the chromium-defect concentration due to yttrium doping. El-Aiat and Kröger proposed yttrium to act as an isoelectronic donor in alumina due to its large radius. ${ }^{25}$ As a result of the donor action of a yttrium ion occupying an aluminum lattice site, the concentration of the aluminum interstitials, assumed to be the majority of aluminum defects, should decrease. Ramanarayanan and Petkovic-Luton proposed that for yttrium addition, to chromia-forming alloys a similar mechanism may occur. ${ }^{26}$ However, this mechanism is very speculative, since the defect chemistry of chromia grown on chromium at the usual oxidation temperatures $\left(900-1100^{\circ} \mathrm{C}\right)$ is not clear. ${ }^{27}$

The reduction in oxidation rate for yttrium-implanted Incoloy $800 \mathrm{H}$ at $960^{\circ} \mathrm{C}$ corresponds well with the findings of Bennett et al. for yttriumimplanted $20 \mathrm{Cr}-25 \mathrm{Ni}-\mathrm{Nb}$ stabilized steel at $950^{\circ} \mathrm{C} .{ }^{28}$ At higher temperatures the effectiveness of yttrium implantation even increases as shown by Bennett et al. ${ }^{28}$ and Przybylski and Yurek. ${ }^{24}$

SIMS and XPS show that for yttrium-implanted Incoloy $800 \mathrm{H}$, the maximum of the yttrium distribution is in the oxide near the alloy/oxide interface. Assuming yttrium to act as a marker, the yttrium distribution shows that the main transport mechanism during oxidation is still cation diffusion, and the reduction of the oxidation rate can therefore only be explained by means of a decreasing cation transport along grain boundaries.

In the case of sulphidation, the effect of yttrium in the preformed oxide is not clear. It was previously stated that yttrium implantation is most effective in the case of oxidation at high temperatures. Evidence for this was presented by Bennett who measured a slightly lower energy of activation for the oxidation of yttrium-implanted $20 \mathrm{Cr}-25 \mathrm{Ni}-\mathrm{Nb}$ stabilized steel compared to nonimplanted steel. ${ }^{27}$ Therefore, it is not likely that the blocking of cation diffusion along grain boundaries is very effective at the temperatures of sulphidation $\left(550-650^{\circ} \mathrm{C}\right)$. Possibly the attack by sulphurous gas species, or sulphur transport along oxide grain boundaries, which is assumed to be the first step in the sulphur transport through oxide scales because of the limited metal diffusion at these temperatures, is affected by rare-earth elements. When the sulphidation does proceed, the sulphidation kinetics are governed by outward metal transport through the sulphide scales formed or sulphide ducts.

The sulphidation tests of Incoloy $800 \mathrm{H}$ show that a decrease in the partial oxygen pressure of the preoxidizing atmosphere gives an improvement in the sulphidation behavior. It is likely that a closed chromia layer is formed. The oxide is therefore less easily converted to sulphides. The 
XPS sputtering profiles show only a slight increase of the chromium content after preoxidation at low partial pressure. This may mean that the structure of the oxide shows less defects due to its higher stability.

\section{The Mechanical Behavior}

Strain-to-cracking of oxide scales can occur due to one or more of the following contributions:

1. Lateral oxide growth, giving rise to crack healing.

2. Elastic deformation.

3. Plastic deformation.

\section{Lateral Oxide Growth}

Schütze derived the following equation for the healing rate of the oxide:

$$
E_{0} h=2 k_{p} / l_{r} \cdot x
$$

where $E_{0} h$ is the critical strain rate, $k_{p}$ the parabolic rate constant, $x$ the distance between the crack face and the metal, and $l_{r}$ the distance between the oxide cracks. ${ }^{29}$

A rough estimate of $E_{0} h$, obtained by taking $k_{p}$ as $3.4 \times 10^{-20} \mathrm{~m}^{2} \mathrm{sec}^{-1}$ at $600^{\circ} \mathrm{C}$ found by means of extrapolation of $k_{p}$ values obtained at higher temperatures, ${ }^{30} l_{r}$ as $10 \mu \mathrm{m}$, and $x$ as $1 \mu \mathrm{m}$, shows that crack-healing by means of lateral oxide growth can occur only below a strain rate of $7 \times 10^{-9} \mathrm{sec}^{-1}$. The effect of lateral oxide growth at the applied strain rate of $4 \times 10^{-7} \mathrm{sec}^{-1}$ can therefore be neglected.

\section{Elastic Deformation}

Only few data are available for the elastic behavior of chromia scales. Schütze estimated that the purely elastic deformation of chromia scales would amount to about $0.09 \%$. $^{31}$ This was based on the values for sintered alumina $^{32}$ and measurements of the elastic modulus for chromia scales. ${ }^{33}$

\section{Plastic Deformation}

According to creep experiments of Burton and Reynolds, ${ }^{34}$ chromia shows plastic behavior above $1200^{\circ} \mathrm{C}$. These measurements were performed on large-grain, high-density chromia rods, sintered at $1600^{\circ} \mathrm{C}$.

In no. 1 it was shown that the absence of strain-to-cracking of the preformed oxide scales up to at least $0.75 \%$ can certainly not be accounted for by lateral oxide growth. The contribution of the elasticity and plasticity of the $1-\mu \mathrm{m}$ thick oxide scales might be significantly higher than the values assumed in nos. 2 and 3. 
Kofstad showed that $50-\mu \mathrm{m}$ thick, fine-grain chromia scales, formed at $1000^{\circ} \mathrm{C}$ in $10^{-7}$ bar $\mathrm{O}_{2}$, have an enormous ability to deform without cracking. ${ }^{35}$ The scales detach and balloon away from the metal. Fine-grain chromia scales may therefore also deform plastically at moderate temperatures $\left(600-900^{\circ} \mathrm{C}\right)$ due to grain-boundary sliding.

All values in this work for strain-to-cracking are significantly higher than the values found by Schütze for oxide scales formed on Incoloy $800 \mathrm{H}$ at $800^{\circ} \mathrm{C} .{ }^{31}$ The cross-sections of the oxide scales show that the measurements of Schütze were performed on much thicker oxide scales of approximately $15 \mu \mathrm{m}$. These thicker oxide scales probably show less stress relaxation than the oxide scales investigated in this work, since Evans et al. showed that the stress relaxation for coatings on a substrate is inversely related to the coating thickness and the grain size. ${ }^{36}$

The reason for the much lower strain-to-cracking values observed for the scales preoxidized at low $\mathrm{PO}_{2}$ is not quite clear. From Fig. 11 and 12 it is obvious that scales preoxidized in $\mathrm{H}_{2} / \mathrm{H}_{2} \mathrm{O}$ show more pronounced grain-boundary oxidation than scales formed in $\mathrm{O}_{2}$, leading to locally attached grains forming aggregates which are likely to admit less grainboundary sliding and therefore less scale plasticity, in agreement with the observed scale-cracking behavior.

Another possible explanation is derived from the experiments of Howes and Richardson who observed large tensile stresses on strips of $\mathrm{Fe}-\mathrm{Cr}$ steel, selectively oxidized at one side. ${ }^{37}$ The tensile stresses for a $\mathrm{Fe}-20 \mathrm{Cr}$ alloy were larger than for $\mathrm{Fe}-28 \mathrm{Cr}$ and $\mathrm{Fe}-16 \mathrm{Cr}$ steel. Howes and Richardson attribute the tensile stresses to the formation of $\mathrm{Cr}_{2} \mathrm{O}_{3}$ on top of the initially formed Fe-rich oxide. The difference in molecular volume of $\mathrm{Fe}_{2} \mathrm{O}_{3}$ compared to $\mathrm{Cr}_{2} \mathrm{O}_{3}$ gives rise to tensile stress. Howes and Richardson showed that a small change in the ratio $\mathrm{Fe}_{2} \mathrm{O}_{3}: \mathrm{Cr}_{2} \mathrm{O}_{3}$ may result in a large increase in tensile stress. It is possible that oxidation of Incoloy $800 \mathrm{H}$ at low $\mathrm{PO}_{2}$, giving rise to a chromium-enriched oxide, results in larger tensile stresses than oxidation at high $\mathrm{Po}_{2}$. However, this theory is speculative, since it has not been verified whether the stresses in the oxide layer are compressive or tensile. An exact estimate of the change in composition of the oxide would also require a more precise determination of the oxide composition near the alloy/oxide interface. Due to selective-sputtering effects and the curved oxide/alloy interface, it is hard to obtain this information from the measured XPS spectra.

\section{CONCLUSIONS}

- Preoxidation of Incoloy $800 \mathrm{H}$ in a mixture of $\mathrm{H}_{2} / \mathrm{H}_{2} \mathrm{O}$ is very effective in reducing the sulphidation rate. 
- Yttrium-ion implantation of Incoloy $800 \mathrm{H}$ effectively reduces the oxidation rate and reduces the sulphidation rate if preoxidation at high $\mathrm{PO}_{2}$ is applied after implantation.

- The observed oxidation and sulphidation behavior of yttriumimplanted Incoloy $800 \mathrm{H}$ may be due to the blockage of short-circuit diffusion paths.

- $1-\mu \mathrm{m}$ thick oxide scales of Incoloy $800 \mathrm{H}$ show a large strain-tocracking value due to increased elastic and/or plastic deformation. The smaller strain-to-cracking values for CER experiments on scales formed at low $\mathrm{PO}_{2}$ are suggested to be due to selective oxide grainboundary growth.

\section{ACKNOWLEDGMENTS}

The University of Groningen provided the implantation facility. We particularly wish to thank J. Smit for ion implanting the specimens. Dr. E. G. Keim is acknowledged for the XPS spectra measured at the University of Twente. The SGM foundation is thanked for putting their SIMS facility at our disposal. D. Gras is especially thanked for his assistance.

\section{REFERENCES}

1. T. Fransen, M. M. A. Perik, H. Fikkert, M. A. de Jongh, and P. J. Gellings, 8th. European Corrosion Congress Nice 53-1 (1985).

2. T. Fransen, E. A. Polman, M. M. A. Perik, and P. J. Gellings, Proceedings "International Congress for High Temperature Alloys and other Gas Applications" Liege 1173 (1986).

3. T. Fransen, M. A. de Jongh, M. M. A. Perik, and P. J. Gellings, Proc. 9th Internat. Congress Metal. Corros. Toronto 4, 311 (1984).

4. T. Fransen, P. J. Gellings, J. C. Fuggle, G. van der Laan, J. M. Esteva, and R. C. Karnatak, Appl. Surface Sci. 20, 257 (1985).

5. M. J. Bennett, G. Dearnaley, M. R. Houlton, R. W. M. Hawes, P. D. Goode, and M. A. Wilkins, Corrosion Sci. 20, 73 (1980).

6. M. J. Bennett, G. Dearnaley, M. R. Houlton, and R. W. M. Hawes, in V. Ashworth, W. A. Grant, and R. P. M. Procter (eds.), Proceedings of the Conference On Ion Implantation into Metals (Pergamon, Oxford, 1982), p. 264.

7. M. J. Bennett, B. A. Bellamy, C. F. Knights, N. Meadows, and N. J. Eyre, Mat. Sci. Engin. 69, 359 (1985).

8. J. C. Pivin, C. Roques-Carmes, J. Chaumont, and H. Bernas, Corrosion Sci. 20, 359 (1980).

9. J. H. Kort, T. Fransen, and P. J. Gellings, Appl. Surface Sci. 25, 237 (1986).

10. E. A. Polman, T. Fransen, and P. J. Gellings, Mat. Sci. Engin. 88, 157 (1987).

11. F. H. Stott, F. M. F. Chong, and C. A. Stirling, 9th Internat. Congress Metal. Corros. 2, 1 (1984).

12. P. J. Gellings, internal report.

13. H. Hindam and D. P. Whittle, J. Electrochem. Soc. 130, 1519 (1983).

14. E. A. Polman, T. Fransen, and P. J. Gellings, to be published.

15. I. Barin and C. Knacke, in Thermodynamical Properties of Inorganic Substances (SpringerVerlag, Berlin, 1973).

16. C. K. Jørgensen and H. Berthou, J. Chem. Soc. Faraday Discuss. 54, 269 (1954). 
17. C. D. Wagner, L. E. Davids, M. V. Zeller, J. A. Taylor, R. M. Raymond, and L. H. Gale, Surf. Interface Anal. 3, 211 (1981).

18. H. Berthou and C. K. Jørgensen, Analyt. Chem. 47, 482 (1975).

19. D. P. Whittle and J. Stringer, Phil. Trans. Royal Soc. London A295, 309 (1980).

20. D. P. Moon and M. J. Bennett, AERE report R 12757.

21. J. Stringer and I. G. Wright, Oxid. Met. 5, 59 (1972).

22. C. M. Cotell, G. J. Yurek, R. J. Hussey, D. F. Mitchell, and M. J. Graham, J. Electrochem. Soc. 134, 1871 (1987).

23. A. Atkinson and R. I. Taylor, NATO ASI Series B 129, 285 (1984).

24. K. Przybylski, A. J. Garratt-Reed, and G. J. Yurek, J. Electrochem. Soc. 135, 509 (1988).

25. M. M. El-Aiat and F. A. Kröger, J. Am. Ceramic Soc. 66, C-202, (1983).

26. T. A. Ramanarayanan and R. Petkovic-Luton, Berichte der Bunsengeschellschaft der Physische Chemie 89, 402 (1985).

27. E. A. Polman, T. Fransen, and P. J. Gellings, J. Physics $C$ (in press).

28. M. J. Bennett, H. E. Bishop, P. R. Chalker, and A. T. Tuson, Mat. Sci. Engin. 90,177 (1987).

29. M. Schütze, Oxid. Met. 25, 409 (1986).

30. J. C. Langevoort, thesis, University of Twente (1985).

31. M. Schütze, Oxid. Met. 24, 199 (1985).

32. G. V. Samsonow, ed., The Oxide Handbook (IFI/Plenum, New York, 1973).

33. R. C. Hurst and P. Hancock, Korrosion 24, 33 (1973).

34. B. Burton and G. L. Reynolds, J. Mat. Sci. 13, 219 (1978).

35. P. Kofstad and K. P. Lillerud, J. of the Electrochem. Soc. 127, 2410 (1980).

36. A. G. Evans, G. B. Crumley, and R. E. Demaray, Oxid. Met. 20, 193 (1983).

37. V. R. Howes and C. N. Richardson, Corrosion Sci. 9, 385 (1969). 